\title{
THE DISTINCTION BETWEEN DEVELOPMENT AND HEREDITY IN INBREEDING
}

DR. EDWARD M. EAST

The Connecticut Agricultural Experiment Station

THERE is among animal breeders a tendency to frequent out-crossing as a preventive of a feared deterioration of the breed through inbreeding. This fear is of long standing, probably having arisen contemporary with, or as a result of, the repugnance to incest possessed by so many human tribes. This general state of mind on the ethical question has brought about an unwarranted belief that there is a physiological law opposed to inbreeding per se. Inbreeding undoubtedly results in many cases of deterioration, but the success of the few daring spirits that have inbred superior stock shows that the cases of deterioration were merely made possible by the course pursued, and were not its direct and constant result.

In the vegetable kingdom a slightly different state of affairs obtains. Some species thrive under inbreeding while others appear to deteriorate. Maize is reduced in vigor in one generation, so that the difference between selfed and crossed plants is noticeable in seedlings two weeks old. Other natural species have evolved intricate mechanisms whereby they are perpetually self-fertilized, and some have even given up sexual reproduction for parthenogenesis (Taraxacum), and yet have survived in competition by their hardiness and prolificacy. Darwin even found that in species that generally appeared to be injured by inbreeding (Ipomce purpurea and Mimulus luteus), individuals were occasionally produced that were not affected.

The classical researches which included the above observations are familiar to all. Direct comparison of crossed and selfed plants, and investigations into the mechanical means by which plants are cross-fertilized, 
all pointed to the truth of the dictum "Nature abhors perpetual self-fertilization," which, by the way, simply corroborated the results that Knight had obtained a half century before. That there are important exceptions to this rule was recognized, however, and Hays, ${ }^{1}$ arguing from the case of wheat, suggested that it be changed to read: "Nature abhors a radical change which would require species to cross in much closer or in much more radical relationship than is their long established habit." Each of these sayings is probably correct as far as it goes. Nature does seem to have provided more for cross-fertilization than self-fertilization. Yet the very fact that all species do not cross-fertilize naturally, shows that although cross-fertilization may be a desirable thinga thing to be provided for by nature-it does not follow that inbreeding and decrease in vigor hold the relation of cause and effect because they are often linked together.

As a matter of fact, the data that we possess regarding the supposed degeneration through inbreeding do admit an entirely different explanation, an explanation more compatible with contemporary knowledge. The hypothesis, first suggested by Shull, ${ }^{2}$ is that the danger from self-fertilization in naturally cross-bred species may be due simply to the isolation of biotypes. It is an established fact, although the cause is unknown, that crosses between nearly related types (in both animals and plants) are usually more vigorous than either of the parent types alone. Since inbreeding tends to isolate types homozygous in their characters, these homozygous types, coming from species naturally crossbred, are thus deprived of the stimulus which came through free intercrossing and appear to deteriorate.

A little later the present writer ${ }^{3}$ pointed out that a

${ }^{1}$ Hays, W. M. “Plant Breeding." Bull. U. S. D. A. Div. Veg. Phy. \& Path. 29: 1901.

'Shull, G. H. "The Composition of a Field of Maize." Ann. Rpt. Amer. Breeders' Assn. 4: 1908.

${ }^{3}$ East, E. M. "Inbreeding in Corn," Ann. Rpt. Conn. Agr. Exp. Station, 1907-8. 
reconsideration of the work of Darwin and others shows that it accords with this theory. As a single example from Darwin we may consider the experiments with Ipomca purpurea, which were his longest, being carried on as they were for ten generations. If an actual degeneration were taking place it might be expected that the difference in height between the crossed and the selfed plants should have gone on increasing in the later generations. Such was not the case, however, and Darwin himself remarked upon it. Nevertheless, the results obtained were what should have been expected by the hypothesis just given, for after a few generations even the crossed plants in such a small lot would have become more or less inbred, and would have approached the inbred stock in size. In further support of this view it is noticeable that the crossed flowers varied in color in the earlier generations, but became more uniform toward the end of the experiment, while the selfed plants were uniform in color throughout the whole time. This, then, explains why his out-crosses with other stock showed greater vigor than did cross-fertilization within a type, the latter strain having become more nearly identified with the selfed plants through continued close breeding.

Such results as the above from Darwin, my own experiments with maize and tobacco, together with the ready agreement of the facts in other breeding work with which I am familiar, indicate that this problem of degeneration combines two questions; the one a question of heredity, the other a question of development. Davenport ${ }^{4}$ has recently called attention to what I consider the former question, suggesting that deterioration through inbreeding may be due to the isolation of homozygous recessives, or the combination of recessive di-hybrids. This is undoubtedly true when the allelomorphic pair under consideration is the presence and absence of something essential to the normal development of the organ-

${ }^{4}$ Davenport, C. B. "Degeneration, Albinism and Inbreeding." Science, N. S., 28: 454, 455, 1908. 
ism. But the principle will probably be found to apply also where there is presence of an abnormal dominant character. We do not know many such characters at present, but susceptibility to rust in wheat and congenital cataract in man may be cited as approaching our meaning.

The instances where the presence or absence of evil qualities is brought to notice through their isolation by inbreeding are few in number, however, and can not account for the large number of cases where there is a loss of vigor by this means.

Let us consider just what this deterioration, so-called, is. Does it represent an actual degeneration in hereditary characters? In general it does not. Darwin's experiments consisted mainly in comparing heights of plants. His measure of vigor, then, is a measure of rapidity and amount of cell division. In no cases does he speak of losses of characters, and seldom of disease. Even where disease appeared, it usually appeared alike in inbred and cross-bred plants. In my own experiments, I have observed some twenty-five families of maize inbred for two generations, and a lesser number through the fourth generation, and have not found a single sign of degeneration. In all characters of stalk, leaves, roots, male inflorescence, female inflorescence, and mature seed, the plants were normal. It is merely in the matter of size of plant and ear, and thereby yield, that the plant compares unfavorably with cross-bred plants.

Further, there is no continuous decline in yield as should be expected in actual degeneration. There is somewhat greater difference between fourth generation inbred and cross-bred plants than there is between those of the second generation. This last fact may be explained by considering the frequency with which heterozygotes in certain characters are selected even in the most careful work. Not all character pairs can be kept under observation, and from the mere fact of its being inbred we can not presume that the isolation of a homozygous strain is complete. The past summer one of our 
fourth-year inbred families was found to be heterozygous in the character pair presence and absence of color in the silk. But there is absolutely no indication that there is loss of vigor after the isolation of a homozygous individual.

It seems, then, that this type of degeneration (the common type) is limited to a partial loss of power of development, a reduction in rapidity and amount of cell division. The phenomenon is readily apparent in open fertilized plants like maize, for there the vigorous growing hybrids are continually being formed in nature. When the components of these hybrid strains are isolated by inbreeding, reduction in vigor is immediately seen. In plants like tobacco, which are naturally inbred, no degeneration is suspected, for the natural plants are taken as the standard. There is an increase in vigor, however, when inbred tobacco strains are crossed, and if the $F_{1}$ generation is then taken as a standard, there is a loss of vigor through inbreeding comparable to that which takes place in maize.

Upon what theoretical basis can these facts rest? In the first place, whether or not we accept the theory that the nucleus is the bearer of all hereditary characters, nevertheless we must believe that amphimixis has two functions, the one a recombination of hereditary characters, and the other a stimulation to development. If we postulate that there is an increase in this stimulation when two strains differing in gametic structure are combined, we satisfy all observed conditions. This will explain why decrease in vigor and not degeneration of characters is usually the sole effect of inbreeding, and will also show why this decrease must reach a limit with the complete isolation of an individual homozygous in all characters, and never will result in a complete degeneration, or "running out," of the strain. One other effect sometimes noticed in inbreeding is also thoroughly in accord with the hypothesis. This is decrease in fertility. Since fertility must necessarily start with the union of 
the gametes and their subsequent division, a decrease in this stimulation in species which have for ages depended upon cross-fertilization may result in decreased fertility.

We can scarcely form a definite idea of the mechanism through which such a stimulation may take place. There may be chemical compounds found in different strains that react when brought together. If this were the case we should expect to find separate families with like "compounds" which when crossed would not be more vigorous than when inbred. It would be difficult to establish such a thing experimentally. On the other hand, the actual fact of difference ${ }^{5}$ in gametic constitution may set up a biological "action" analogous to ionization. If this were true, and individuals of the $F_{1}$ generation heterozygous in all differentiating characters were selected in succeeding generations, there should be no reduction in vigor, while individuals of the $F_{2}$ generation, homozygous in their characters, should compare in vigor to the $P_{1}$ generation. This hypothesis we are testing, but results will necessarily be slow.

The $F_{1}$ generation of thirty maize crosses were grown in 1908 on well fertilized land in Connecticut. They were planted three feet six inches each way, about four stalks to the hill. Seeds from the same parent ears ${ }^{6}$ which were used to make the crosses were also grown for comparison. Only fifty hills of each of the crosses and of each parent could be grown on account of limited space, but the soil conditions were such that a very fair

5 The objection will be raised that beyond a certain amount of difference between gametes, there will be sterility. It is generally true that there is sterility with wide differences in botanical or zoological characters, but there are exceptions, and we must not fall into the same old rut of putting the two down as cause and effect becanse there is at present no other explanation. It is definitely settled that in certain cases the bar to fertility is merefy the mechanical inability of the spermatazoon to penetrate the ovum. It seems reasonable that the stimulation effect may be illustrated by borrowing Galton's polyhedron.

${ }^{6}$ The parent ear's were, therefore, one year older, but their germination was good, and their growth equal to inbred seed of the same ages as the hybrid seed. 
indication of the comparative vigor of each strain was obtained. Unfortunately crows and chipmunks played havoc with the "stand" in a number of cases, and accurate figures can not be given except in the following four cases where the stand was perfect.

A white dent no. 8 yielded 121 bushels per acre (at 70 pounds per bushel); a yellow dent no. 7 , which had been inbred artificially for three years, yielded 62 bushels per acre; the cross between the two varieties, no. $7 q \times$ no. 8 o, yielded 142 bushels per acre.

Longfellow, no. 34, an eight-rowed, yellow flint yielding 72 bushels per acre, was crossed with the same no. 8 white dent, yielding 121 bushels per acre; the resulting cross yielded 124 bushels per acre.

Sturges's hybrid, a twelve-rowed, yellow flint with a tall, non-branching stalk partaking of the characters of dent varieties, was also crossed with no. 8 white dent. The flint parent yielded 48 bushels per acre, while the cross yielded 130 bushels per acre.

Two families of a yellow dent variety, which had each been inbred artificially for three years, were the parents of the fourth cross. No. 12, yielding 65 bushels per acre, was crossed with no. 7 , yielding 62 bushels per acre. The $F_{1}$ generation vielded 202 bushels per acre. This last result is somewhat distorted, as five stalks per hill of the cross were allowed to grow while of the parents only four seeds per hill were planted. About 90 per cent. of the seeds produced mature stalks. Notwithstanding the closeness of planting to which this cross was subjected, however, casual observation was sufficient to show that it soared far beyond each parent in vigor of plant and size of ear.

In the remainder of the field every possible combination of dent, flint and sweet maize was grown, and in every case an increase in vigor over the parents was shown by the crosses. It is to be regretted that comparable yields could not be obtained in every instance, but, as a matter of fact, the differences were so apparent 
to the eye that it is almost unnecessary. The figures presented do not show the average increase to be expected by a cross. The manuring was heavy, the cultivation intensive, and the yields were beyond the ordinary. But they do show that in practically every case a combination of two high-bred varieties of seed corn is more vigorous than either parent.

The importance of this fact in commercial corn growing is considerable, and is likely to increase in the future, for the following reason. The corn breeding methods in use vary as to detail, but their purpose is the same, namely, to produce high-yielding strains. The older idea was that continued selection of plus fluctuations would invariably yield results. At present, there are more adherents to the view that man can do more than isolate from the mixture of types we call a commercial variety the most perfect type that nature has produced in this variety. It is all line breeding, and as it is carried on on small plots, the tendency toward the production of an inbred strain increases with the length of time the work is prosecuted. Thus, unless new mutations intervene, chance of improvement is limited to the latent possibilities of the first breeding plot.

Shull has already suggested that either definite recombination of previously isolated biotypes, or relaxation of selection after partial isolation and rejection of the less efficient biotypes, will be found to be the logical procedure in corn breeding.

The writer has become a convert to the first method

'Since this manuscript was sent to the printer the writer received from Dr. Shull, as a timely coincidence, a copy of a paper that he had read at the annual meeting of the American Breeder's' Association, in January, 1909. In it he deals with a similar method of corn-breeding, namely, the actual isolation of homozygous strains by artificial inbreeding, and their recombination later. His method is more correct theoretically, but less practical than that of the writer. From this paper I inferred that his views must accord with the theory presented in this paper. Replies to my inquiries show that our ideas are strictly in harmony, although Dr. Shull had not treated the theoretical phase of the subject, having considered it as beyond the scope of his paper. 
in a modified form, and suggests the following scheme. There must always be corn specialists to continue line breeding, and this method is not for the corn breeder, but the corn grower. The latter should purchase from the line breeder two strains of seed each year, and grow the $F_{1}$ generation of the cross between them.

The method requires a small isolated hybridization plot in addition to the commercial field. In this plot the two strains are planted in alternate rows. The male inflorescence is removed from one strain at flowering time and all of the seed for the commercial field selected from this crossed strain. Some hybrid combinations will be found to be more vigorous than others, but I am convinced that practically any cross within the subspecies will be profitable. Crosses between the subspecies, while more vigorous than the mean between the parents, have certain disadvantages, such as variation in the time of ripening, which make them less desirable for practical use. 